\title{
DUCTILITY OF HIGH PERFORMANCE STEEL MOMENT CONNECTIONS
}

\author{
Ana M. Girão Coelho ${ }^{1,2, *}$ and Frans S. K. Bijlaard ${ }^{2}$ \\ ${ }^{1}$ Department of Civil Engineering, Polytechnic Institute of Coimbra \\ Rua Pedro Nunes, 3030-199 Coimbra, Portugal \\ ${ }^{2}$ Structural and Building Engineering, Faculty of Civil Engineering, Delft University of Technology \\ PO Box 5048, 2600 GA Delft, The Netherlands \\ *(Corresponding author: Phone: +351 239790312 / +351 964837 943; Fax: +351 239790 311; \\ E-mail:a.m.girao@clix.pt)
}

Received: 23 April 2007; Revised: 2 July 2007; Accepted: 23 July 2007

\begin{abstract}
Recent developments in high performance construction materials have made them attractive for the design of buildings, as light weight and thin elements are desirable for architectural reasons and for the reduction of environmental impacts of construction. Steel framework is a typical structural system in modern buildings. Current analysis and design of steel-framed buildings are usually carried out under the semi-continuous/partially-restrained philosophy. This type of structural modelling is only feasible if the structural joints are designed for rotation capacity and ductility. Members and joints made up of high performance steel exhibit improved strength but limited deformation capacity compared to mild steel grades. Connections between members, in particular, are the regions where the material is exposed to higher deformations demands. The designer then has to ensure that they undergo large inelastic deformations. To address this topic, an experimental investigation was undertaken on moment connections with end plates made from high strength steel grades S460, S690 and S960 (yield stress of $460 \mathrm{MPa}, 690$ $\mathrm{MPa}$ and $960 \mathrm{MPa}$, respectively) to provide insight into the nonlinear behaviour of this joint type. The major contributions of this study are (i) the validation of current Eurocode 3 specifications for the design of joints and (ii) the ductility analysis of high performance steel joints to verify whether they have large plastic deformations.
\end{abstract}

Keywords: Ductility; end plate connections; experimental testing; high-strength steel; resistance; rotation capacity; stiffness

\section{INTRODUCTION}

Steel framework is a typical structural system in modern building construction. In this type of construction, beam-column joints have to transfer the beam and floor loads to the columns. Generally, the forces transmitted through the joints can be axial and shear forces, bending and torsion moments. The bending deformations are predominant in most cases, when compared to axial and shear deformations that are hence neglected. The effect of torsion is also negligible in planar frames. Typical beam-column moment-resisting joints in steel-framed structures include bolted end plate connections, bolted connections with angle cleats and welded connections. The behaviour of these joints is intrinsically nonlinear. This nonlinearity arises because a joint is an assemblage of several components that interact differently at distinct levels of applied loads. The interaction between the elemental parts includes elastoplastic deformations, contact, slip and separation phenomena. The analysis of this complex behaviour is usually approximate in nature with drastic simplifications. Tests (both experimental and numerical) are frequently carried out to obtain the actual response, which is then modelled approximately by mathematical expressions that relate the main structural joint properties. In the case of moment-resisting joints, three properties are usually sufficient for characterization of their behaviour (Figure 1): (i) moment resistance, (ii) rotational stiffness and (iii) rotation capacity. Research work on this subject has been intensive over the past years [1-7]. Emphasis was mainly placed on full strength joints and, therefore, only the resistance and stiffness properties were fully characterized. Rules for prediction of strength and stiffness of this joint type were thus included in modern design codes as the European code of practice for the design of structural steel joints in buildings, part 1-8 of Eurocode 3 [8] (EN 1993-1-8), and the specification for structural steel buildings from the American Institute of Steel Construction [9]. 


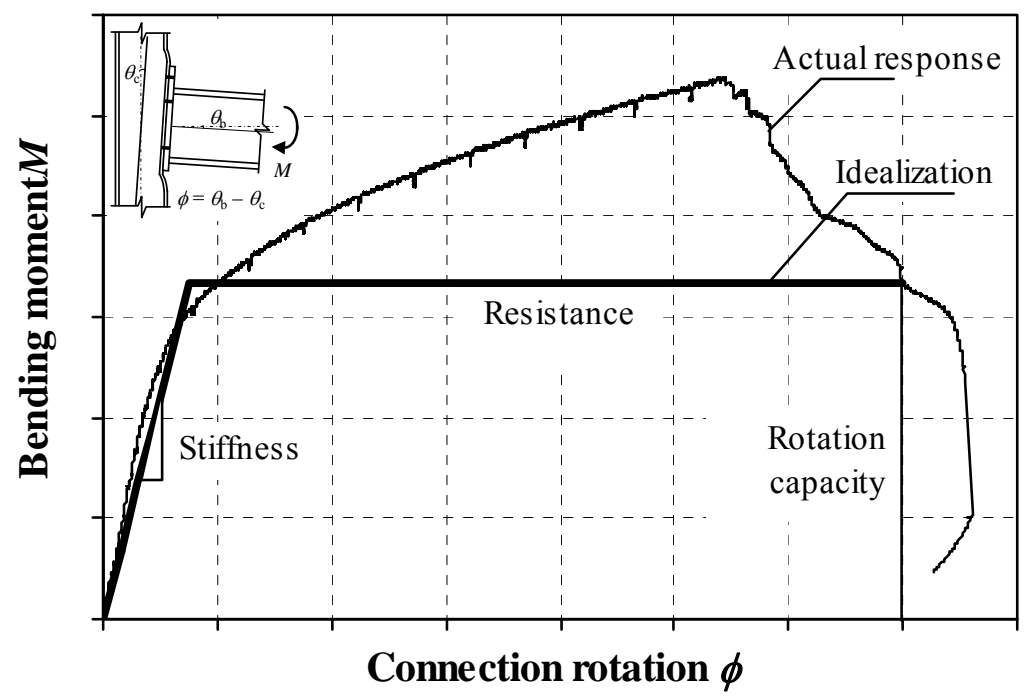

Figure 1. Moment-rotation Response of a Joint (Definitions)

Several authors have recently highlighted the importance of designing structural joints for rotation capacity and ductility [10-13]. The knowledge of the plastic deformation supply of members and joints is particularly important for steel frames that experience abnormal loading conditions, such as fire and seismic events. In these extreme events, very high demands for local and global deformation are imposed on structural elements, connections and details. Connections between members, in particular, are the regions where the material is exposed to higher deformations and, consequently, they influence local ductility requirements and framing performance. EN 1993-1-8 includes simple deemed-to-satisfy criteria to guarantee that the available deformation capacity is higher than the deformation demand of a specific joint. Derivation of such criteria can be found in References 14 and 15. In the context of the component method that considers a joint as an assembly of elemental parts (or components), some researchers have developed simplified approaches to quantify the overall rotation capacity of joints $[7,11,12,16,17]$.

Recent interest in high performance construction materials to produce innovative structures again draws attention to issues related to the deformation capacity of members and, specially, connections. High performance steels (HPS) in construction represent a family of steels with a yield stress above $460 \mathrm{MPa}$ and offer higher performance in tensile stress, toughness, weldability and corrosion compared to mild steel grades [18]. The mechanical characteristics of these steels are different from conventional steels. HPS are generally less ductile and have a smaller (i) yield plateau and (ii) yield stress-to-tensile stress ratio.

Traditionally, the design of structures fabricated from HPS is essentially based on an elastic concept as the service requirements usually govern the structural response. The limit states are then the attainment of the (i) yield stress or (ii) buckling stress at the critical locations. Structural strength and stiffness of members and connections can be derived relatively easily in this case. Designers have however recognized the need to account for inelastic effects directly in structural analysis. Advanced analysis that includes material plasticity, geometric nonlinearities and connection behaviour is then required. Part 1-12 of Eurocode 3 [19] (prEN 1993-1-12) presently forbids elastic-plastic global structural analysis with plastified sections and/or joints acting as plastic hinges. This standard states that the rules for semi-rigid joints are not applicable to HPS and that the resistance of joints should always be based on elastic distribution of forces over the components [19].

Whether or not HPS can be used for plastic design will depend on the outcome of intensive 
research. This motivated an experimental and numerical comprehensive investigation on "HPS in Civil Engineering Structures" that is being carried out at the Department of Structural and Building Engineering of the Delft University of Technology. The research work presented in this paper mainly focus on moment connections employing HPS. Experiments on statically loaded bolted end plate connections were undertaken to provide insight into the behaviour of this connection type. Since an end plate connection comprises several critical components, it was decided to focus this study on the single contribution of the assembly end plate-bolts in the tension zone. These components are modelled as equivalent T-stubs [2,4] (Figure 2). Previous work on similar connection details has shown that the deformation characteristics primarily depends on (i) the connection geometry, particularly the ratio between the end plate thickness $t_{\mathrm{ep}}$, and the bolt diameter $\phi_{b}$, (ii) the assurance of a good material ductility for plate and bolts, (iii) the ratio between the resistance of the plate and the bolt and (iv) the welding quality [7,12,14]. Test results were used to (i) validate current specifications for the design of joints in EN 1993-1-8, within the semi-continuous/partially-restrained concept, (ii) to examine the connection response from a strength and deformation point of view and (iii) to verify whether HPS moment connections develop sufficient rotation capacity for global plastic analysis.

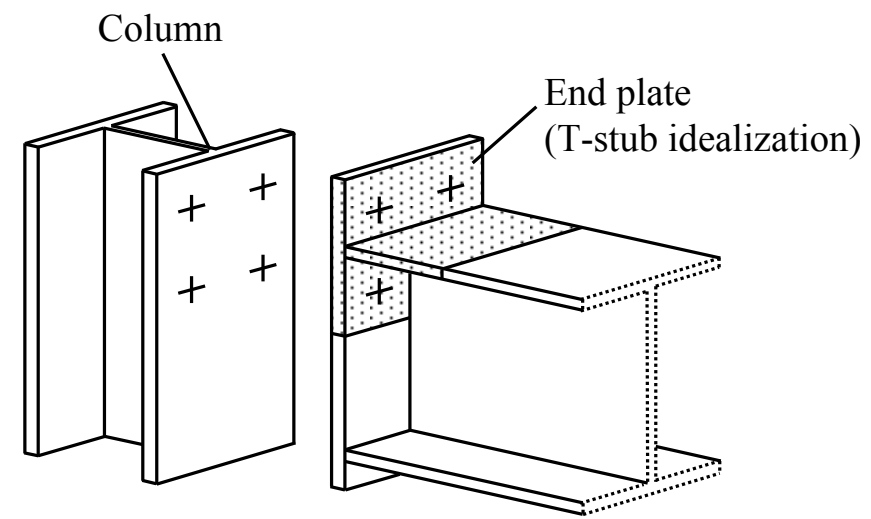

Figure 2. Extended End Plate Connection: T-stub Idealization

This paper specifically deals with the latter topic. A brief description of the experimental programme and results is given. Comparisons with code predictions are also drawn. The paper opens the way for the establishment of requirements for sufficient rotation capacity as well as ductility requirements to avoid brittle failures and concludes by outlining future research that is still required.

\section{EXPERIMENTAL PROGRAMME}

\section{$2.1 \quad$ Test Details}

The experimental programme consisted of seventeen beam-column bolted end plate connections. The specimens were designed to trigger failure in the assembly end plate-bolts in the tension zone without development of the full plastic moment capacity of the beam (partial-strength joint). Beam and column sections are of class 1 [20].

Extended end plate (EEP) and two different flush end plate configurations (F1EP and F2EP) were tested (Figure 3a). For the second flush end plate configuration (F2EP), a detail of the welding to the beam is also given in Figure 3b. A general review and description of the test programme is given elsewhere [21,22]. The relevant details of the test specimens are given in Figure 3c and Table 1. Bolts were hand-tightened to give a snug fit in all sets. 


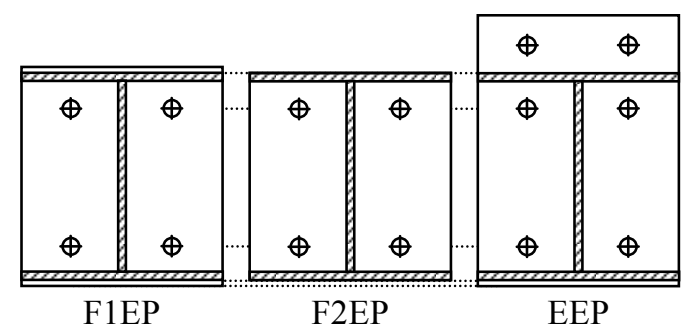

(a) Configurations

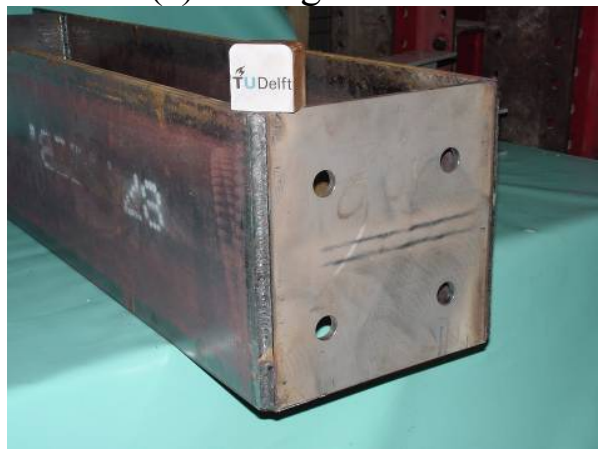

(b) Detail of the Welding of the End Plate to Beam Flange (Outside) for Flush Configuration 2

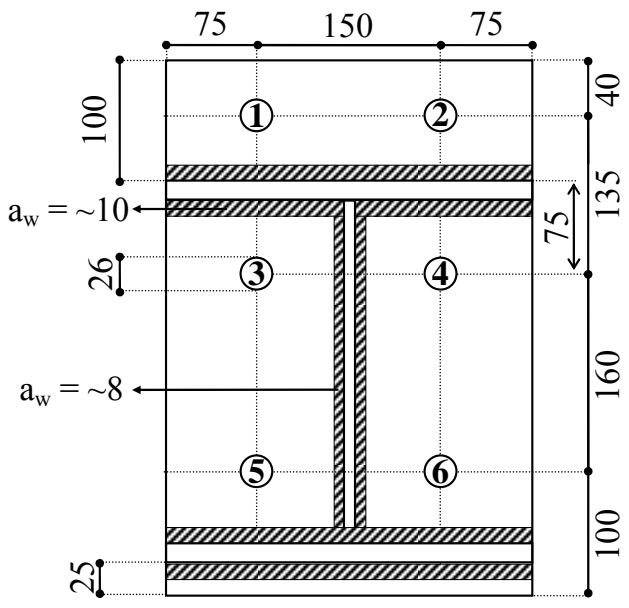

(c) End Plate Dimensions

Figure 3. End Plate Configurations and Dimensions

Table 1. Details of Test Specimens

\begin{tabular}{|c|c|c|c|c|c|c|c|c|c|c|c|c|}
\hline \multirow[t]{2}{*}{ Test ID } & \multicolumn{2}{|c|}{ Column } & \multicolumn{2}{|c|}{ Beam } & \multicolumn{5}{|c|}{ End plate } & \multicolumn{3}{|c|}{ Bolt } \\
\hline & Section & Grade & Section & Grade & $\begin{array}{c}t_{\mathrm{ep}} \\
(\mathrm{mm})\end{array}$ & Grade & $\begin{array}{c}f_{\text {y.ep }} \\
(\mathrm{MPa})\end{array}$ & $\rho_{\mathrm{y}}$ & $\varepsilon_{\mathrm{f}}$ & $\begin{array}{c}\phi_{b} \\
(\mathrm{~mm})\end{array}$ & Grade & $\begin{array}{c}f_{\text {u.b }} \\
(\mathrm{MPa})\end{array}$ \\
\hline $\begin{array}{lll}\text { F1EP } & 15 \quad 1\end{array}$ & HE300M & S355 & HE320A & S355 & 15.30 & S460 & 483 & 0.84 & 0.175 & 24 & 12.9 & 1413 \\
\hline F2EP_15_1 & HE300M & S355 & HE320A & S355 & 15.30 & $\mathrm{~S} 460$ & 483 & 0.84 & 0.175 & 24 & 12.9 & 1413 \\
\hline EEP $\overline{1} 5 \overline{1}$ & HE300M & S355 & HE320A & S355 & 15.25 & S460 & 483 & 0.84 & 0.175 & 24 & 8.8 & 940 \\
\hline F1EP_15_2 & HE300M & S355 & HE320A & S355 & 14.75 & S690 & 774 & 0.95 & 0.186 & 24 & 12.9 & 1413 \\
\hline F2EP_15_2 & HE300M & S355 & HE320A & S355 & 14.64 & S690 & 774 & 0.95 & 0.186 & 24 & 12.9 & 1413 \\
\hline EEP $15 \overline{2}$ & HE300M & S355 & HE320A & S355 & 14.62 & S690 & 774 & 0.95 & 0.186 & 24 & 12.9 & 1413 \\
\hline $\begin{array}{l}\text { F1EP } 102 \\
\end{array}$ & HE300M & S355 & HE320A & S355 & 10.15 & S690 & 698 & 0.93 & 0.175 & 24 & 12.9 & 1413 \\
\hline F2EP_10_2 & HE300M & S355 & HE320A & S355 & 10.25 & S690 & 698 & 0.93 & 0.175 & 24 & 12.9 & 1413 \\
\hline EEP_10_2a & HE300M & S355 & HE320A & S355 & 10.10 & S690 & 698 & 0.93 & 0.175 & 24 & 12.9 & 1413 \\
\hline $\mathrm{EEP} 10 \_2 \mathrm{~b}$ & HE300M & $\mathrm{S} 355$ & HE320A & S355 & 10.10 & S690 & 698 & 0.93 & 0.175 & 24 & 8.8 & 940 \\
\hline $\begin{array}{llll}\text { F1EP } & 10 & 3\end{array}$ & HE300M & S355 & HE320A & S355 & 10.00 & S960 & 952 & 0.91 & 0.154 & 24 & 12.9 & 1413 \\
\hline F2EP $10-3$ & HE300M & S355 & HE320A & S355 & 10.00 & S960 & 952 & 0.91 & 0.154 & 24 & 12.9 & 1413 \\
\hline EEP $10 \overline{3}$ & HE300M & $\mathrm{S} 355$ & HE320A & S355 & 10.00 & S960 & 952 & 0.91 & 0.154 & 24 & 12.9 & 1413 \\
\hline F2EP 10 2(M27) & HE300M & S355 & HE320A & S355 & 10.05 & S690 & 698 & 0.93 & 0.175 & 27 & 8.8 & 1013 \\
\hline EEP $\overline{1} 0 \overline{2}(\mathrm{M} 27)$ & HE300M & S355 & HE320A & S355 & 10.10 & S690 & 698 & 0.93 & 0.175 & 27 & 8.8 & 1013 \\
\hline F2EP_10_3(M27) & HE300M & S355 & HE320A & S355 & 10.00 & S960 & 952 & 0.91 & 0.154 & 27 & 8.8 & 1013 \\
\hline EEP $10 \_3(\mathrm{M} 27)$ & HE300M & $\mathrm{S} 355$ & HE320A & $\mathrm{S} 355$ & 10.03 & S960 & 952 & 0.91 & 0.154 & 27 & 8.8 & 1013 \\
\hline
\end{tabular}


The actual mechanical properties for the end plates and bolts are also given in Table $1\left(f_{\mathrm{y}}\right.$ : yield stress; $f_{\mathrm{u}}$ : tensile stress; $\rho_{\mathrm{y}}=f_{\mathrm{y}} / f_{\mathrm{u}}$ : yield ratio; $\varepsilon_{\mathrm{f}}$ : strain at rupture load). The constitutive law of the several classes of HPS is plotted in Figure 4.

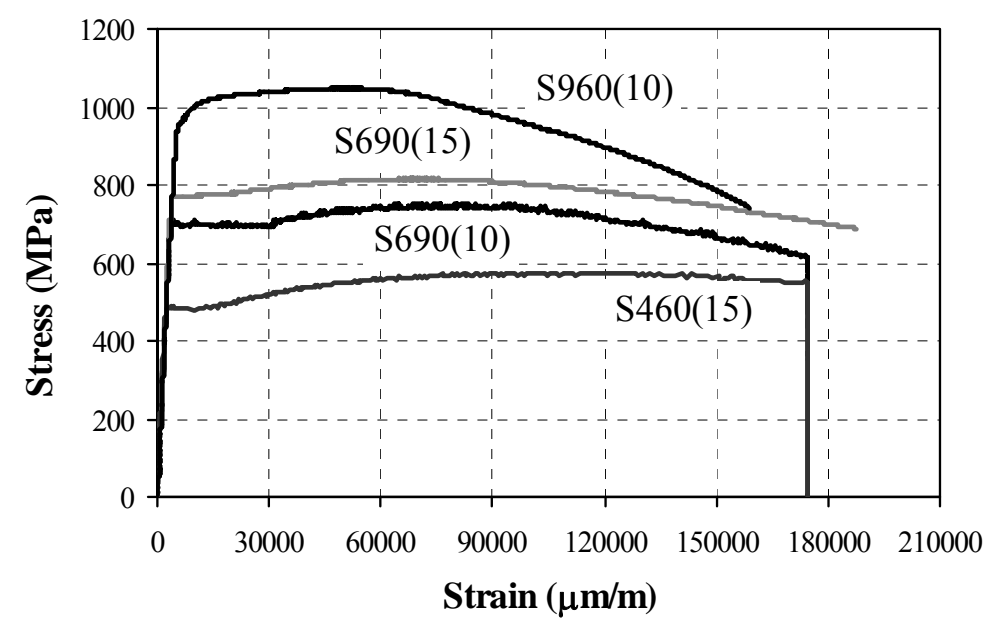

Figure 4. Stress-strain Behaviour of the End Plate Material

\subsection{Moment-rotation Curves and Failure Modes}

The behaviour of moment connections is typically represented by a moment-rotation curve that describes the relationship between the applied bending moment, $M$ and the corresponding rotation between the members, $\phi$. Figure 5 illustrates a typical moment-rotation response of the connections tested. This curve defines three main structural properties: (i) (plastic and ultimate) moment resistance, $M_{\mathrm{j} . \mathrm{R}}$ and $M_{\mathrm{j} . \mathrm{max}}$, (ii) (initial and post-yield) rotational stiffness, $S_{\mathrm{j} . \text { ini }}$ and $S_{\mathrm{j} . \mathrm{p}-1}$ and (iii) rotation capacity, $\phi_{\mathrm{C}}$. The characteristics of these curves for the several test details are set out in Table 2. The failure modes of the specimens are also indicated in the table: (i) mode A: cracking of the end plate in the heat affected zone, (ii) mode B: bolt-thread stripping and (iii) mode C: bolts in tension. Illustration of these modes of failure is given in Figure 6.

The $M-\phi$ response for representative test specimens is given in Figure 7. Several conclusions can be drawn from the analysis of these graphs and the curves properties in Table 2:

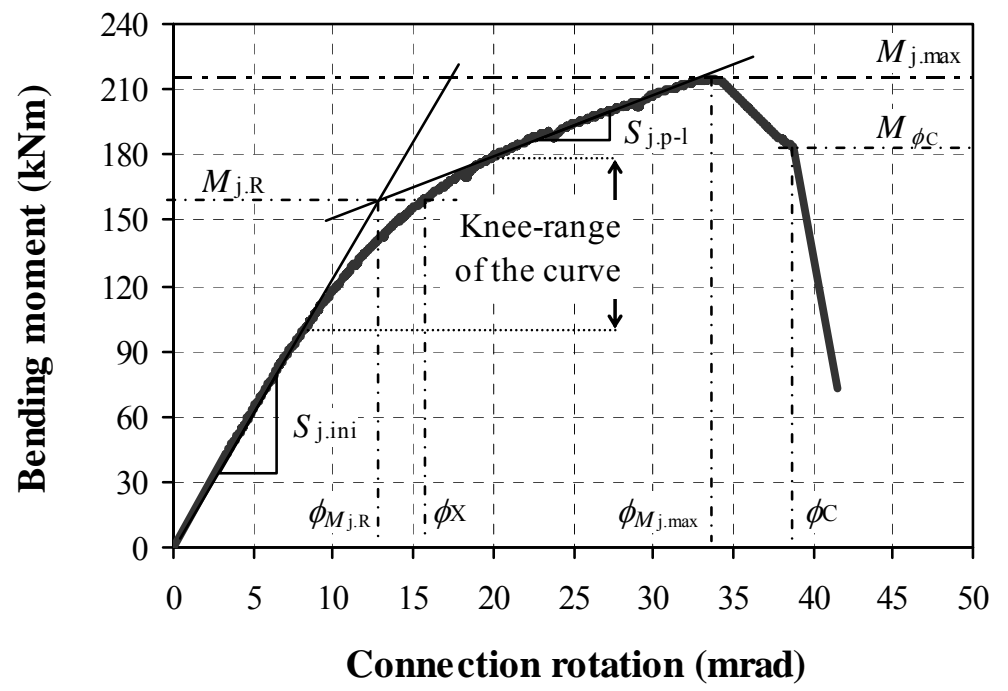

Figure 5. Typical Moment-rotation Response (e.g. F2EP_15_2) 
Table 2. Main (Experimental) Characteristics of the Moment-rotation Curves

\begin{tabular}{|c|c|c|c|c|c|c|c|}
\hline \multirow[t]{2}{*}{ Test ID } & \multicolumn{2}{|c|}{ Stiffness $(\mathrm{kNm} / \mathrm{mrad})$} & \multicolumn{2}{|c|}{ Resistance (kNm) } & \multicolumn{2}{|c|}{ Rotation capacity (mrad) } & \multirow[t]{2}{*}{ Failure mode } \\
\hline & $S_{\mathrm{j} . \mathrm{ini}}$ & $S_{\text {j.p-1 }}$ & $M_{\mathrm{j} . \mathrm{R}}$ & $M_{\mathrm{j} \text {.max }}$ & $\phi_{M_{j \max }}$ & $\phi_{\mathrm{C}}$ & \\
\hline F1EP_15_1 & 18.4 & 0.18 & 192 & 198 & 33 & 33 & Mode A \\
\hline F2EP_15_1 & 12.7 & 2.1 & 128 & 172 & 32 & 40 & Mode A \\
\hline EEP $15 \overline{1}$ & 30.0 & 3.3 & 270 & 326 & 28 & 28 & Mode B \\
\hline $\begin{array}{lll}\text { F1EP } & 15 & 2\end{array}$ & 14.1 & 2.6 & 175 & 231 & 34 & 37 & Mode $\mathrm{C}$ \\
\hline F2EP 152 & 12.3 & 2.6 & 160 & 215 & 33 & 39 & Mode C \\
\hline EEP $15 \overline{2}$ & 35.3 & 9.7 & 245 & 366 & 20 & 20 & Mode C \\
\hline $\begin{array}{llll}\text { F1EP } & 10 & 2\end{array}$ & 7.8 & 1.9 & 95 & 142 & 39 & 46 & Mode A \\
\hline $\mathrm{F} 2 \mathrm{EP}^{-} 10^{-} 2$ & 7.2 & 1.4 & 89 & 117 & 35 & 41 & Mode A \\
\hline EEP $\overline{1} 0 \overline{2} \mathrm{a}$ & 17.2 & 3.2 & 173 & 244 & 36 & 45 & Mode A \\
\hline EEP_10_2b & 19.9 & 5.4 & 188 & 252 & 37 & 46 & Mode A \\
\hline F1EP_10_3 & 9.3 & - & 171 & 201 & 46 & 46 & Mode C \\
\hline F2EP_10_3 & 8.0 & 0.8 & 155 & 176 & 52 & - & Mode C \\
\hline EEP $10 \overline{3}$ & 20.7 & 4.0 & 235 & 326 & 38 & 38 & Mode C \\
\hline F2EP_10_2(M27) & 7.2 & 1.3 & 98 & 130 & 38 & 38 & Mode A \\
\hline EEP 102 (M27) & 23.2 & 3.4 & 195 & 266 & 30 & 52 & Mode A \\
\hline F2EP_10_3(M27) & 10.9 & 1.9 & 123 & 173 & 42 & 67 & Modes A\&C \\
\hline EEP 10 3(M27) & 23.0 & 3.7 & 253 & 314 & 31 & 44 & Mode A \\
\hline
\end{tabular}
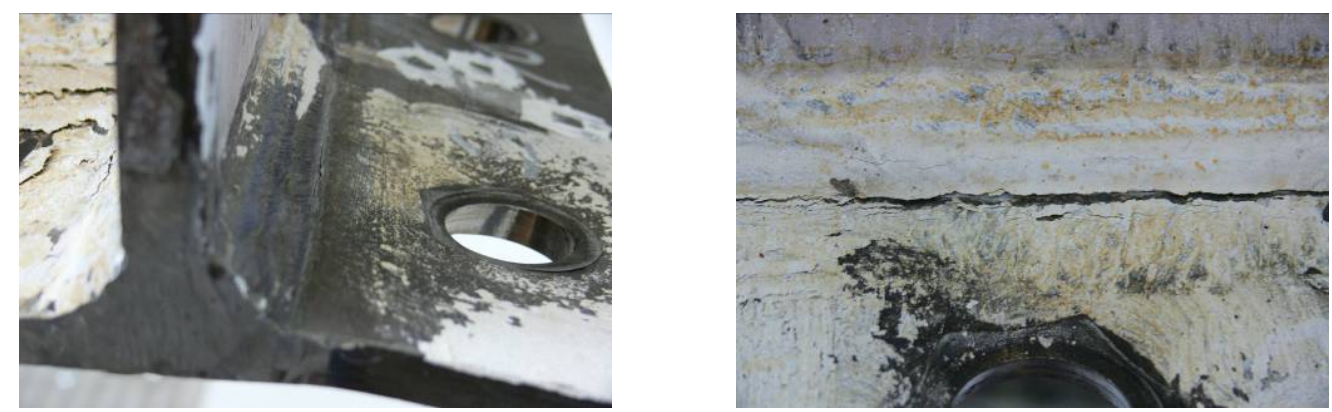

(a) Mode A: Cracking of the End Plate in the Heat Affected Zone (Specimen EEP_10_2(M27))
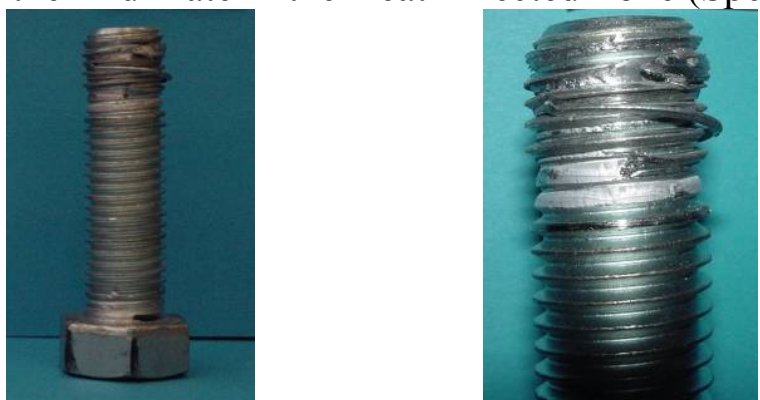

(b) Mode B: Bolt-thread Stripping (Specimen EEP_15_1, bolt \#3)

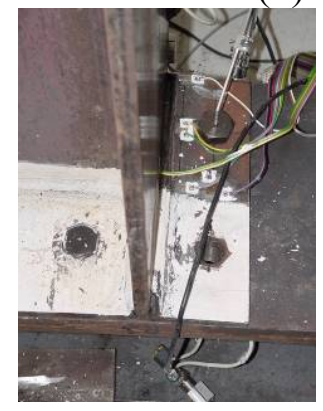

Specimen F1EP_15_2

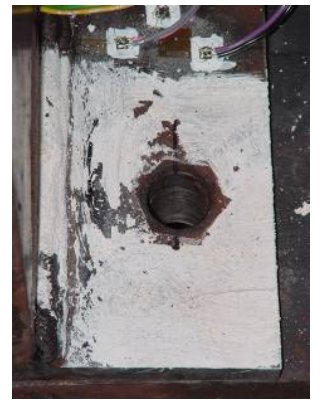

(c) Mode C: Bolts in Tension

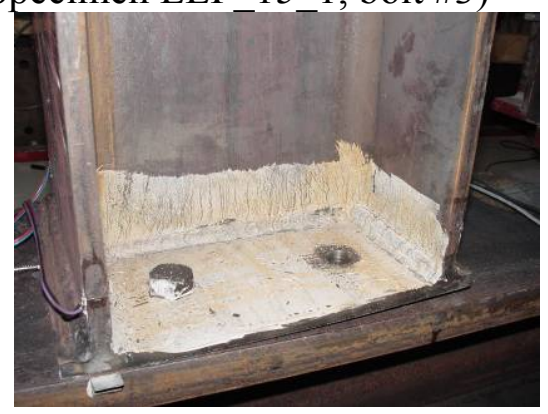

Specimen EEP_15_2 (general view and detail)

Figure 6. Illustration of the Failure Modes 

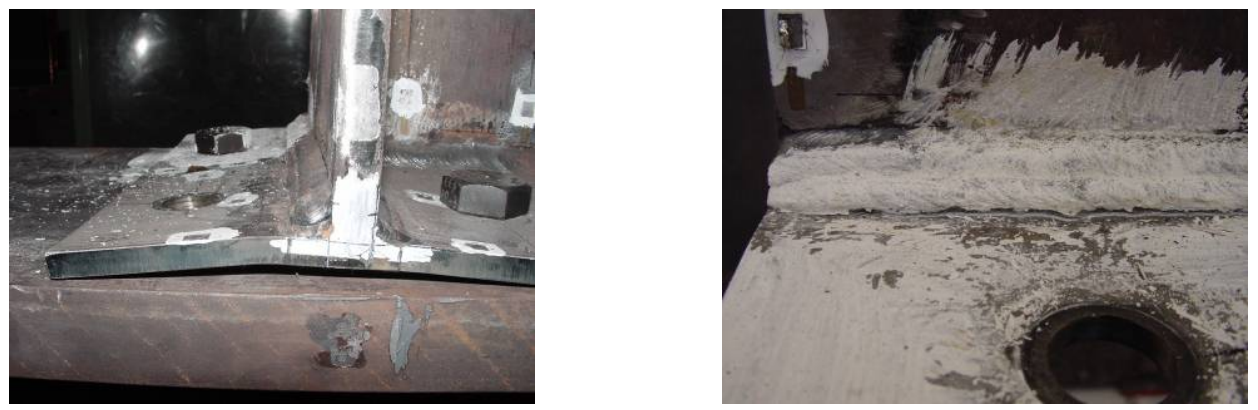

(d) Combined Failure Modes A and C (Specimen EEP_10_3)

Figure 6. Illustration of the Failure Modes (cont.)

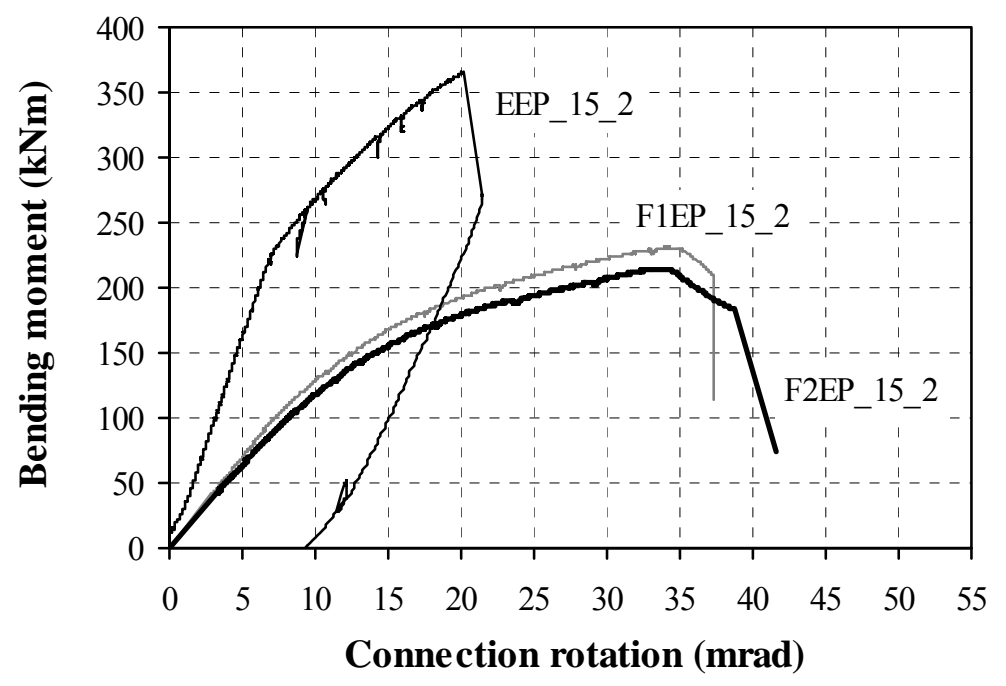

(a) $15 \mathrm{~mm}$ End Plates, S690

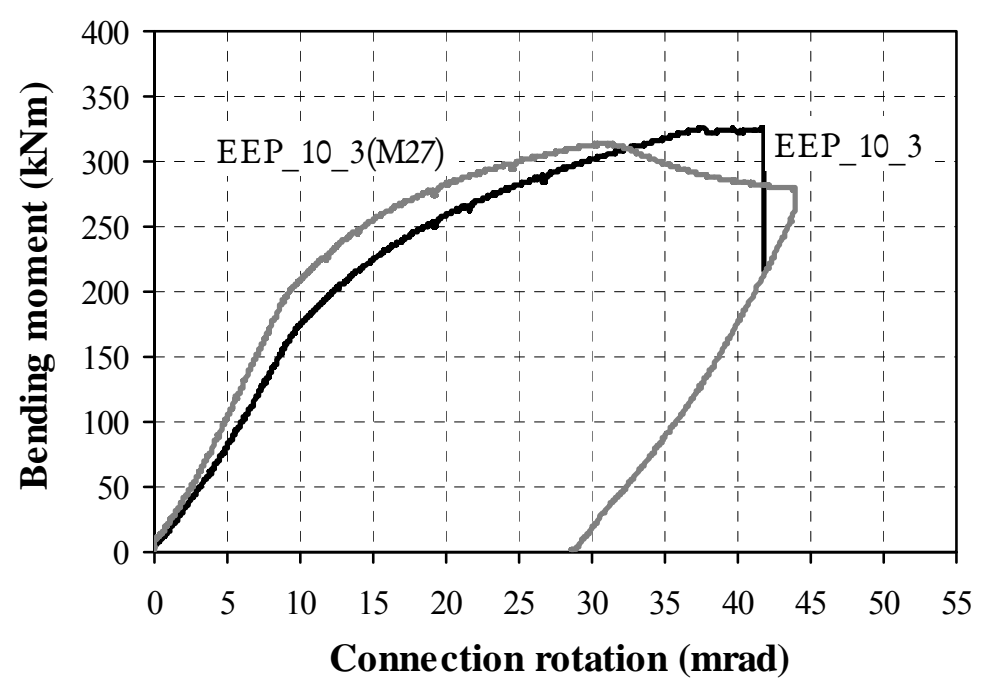

(b) $10 \mathrm{~mm}$ Extended End Plates, S960

Figure 7. Moment-rotation Curves for Specimens Employing S690 and S960

1. The rotational stiffness of the joints increases with the end plate thickness; because this property mainly depends on the Young modulus, there are no relevant variations with the plate steel grade.

2. The moment resistance enhances with the end plate thickness and the plate steel grade.

3. The rotation capacity decreases with the thickness of the plate; in general, it also decreases with the plate steel grade, though this variation is also linked to the governing failure mode. 
4. The behaviour of the two flush end plate configurations is identical over the entire elastoplastic range (Figure 7a).

5. The behaviour of extended end plate joints is much stiffer than "parent" flush end plate configurations; moment resistance is also larger but the deformation capacity is smaller (Figure 7a).

6. The joint performance, in terms of resistance and stiffness, with bolts M24 grade 12.9 and bolts M27 grade 8.8 is equivalent; however, from a ductility point of view, bolt grade 8.8 should be taken (Figure 7b). Bolts 12.9 exhibited very limited ductility and hardly any deformation in bending. In fact, in some cases (e.g. specimens with extended end plates) failure of the bolt occurred due to excessive rotation near the bolt head. Therefore, a strong recommendation against the use of this class of bolts is made.

The usual bolt diameter/end plate thickness combination for mild steel grades (e.g. bolts M24 in 15 $\mathrm{mm}$ plates) was checked for cases where HPS was present. Alternatively, the test programme included M27 8.8 bolts in $10 \mathrm{~mm}$ end plates, to check whether the overall ductility improved. In the latter case, very strong bolts were used in relatively thin end plates. The results however were rather disappointing since the rotation capacity did not increase as expected. The overall behaviour was dominated by cracking of the plate in the heat affected zone.

\section{VERIFICATION OF EUROCODE 3 PREDICTIONS ON TEST RESULTS}

The design of joints made up of HPS up to S700 is covered in prEN 1993-1-12, as mentioned above. This pre-norm does not allow the design of HPS joints within the semi-continuous/partially-restrained concept [19]. Experiments have however shown that yielding of the end plate also occurs with HPS S690 or S960. Still, the adoption of this type of structural modelling for global analysis is only adequate if the joint develops sufficient rotation capacity so that a ductile failure mechanism of the whole structure can be formed prior to fracture of the joint. Literature shows that end plate connections can achieve rotation capacity provided that the end plate is a "weak link" relative to the bolts $[12,14,23]$. The conclusions however were validated for mild steel grades. Current tests employ end plates and bolts with similar mechanical properties, in terms of yield stress and yield ratio. It has to be investigated whether this influences the above premises.

In this section, a comparison between test results and current EN 1993-1-8 design provisions is undertaken. The code gives quantitative rules for the prediction of the joint flexural plastic resistance and initial stiffness. These structural properties are evaluated below by using the actual geometrical and mechanical properties [21]. The recommendations on rotation capacity are also verified to investigate if there is enough rotation capacity according to EN 1993-1-8. The provisions are compared with the test results below. The partial safety factors were taken as unitary.

The initial stiffness is evaluated in the framework of the component method. The method is illustrated in Figure 8 for the case of bolted extended end plate connections (with two bolt rows in tension). For the computation of the joint rotational stiffness, the active joint components for this configuration, according to EN 1993-1-8 are: column web in shear (cws), column web in compression (cwc), column web in tension (cwt), column flange in bending (cfb), end plate in bending (epb), and bolts in tension (bt). The welds connecting the end plate and the beam are not taken into account for computation of the rotational stiffness, as well as components beam web and flange in compression (bfc) and beam web in tension (bwt). The basic joint components are modelled by means of extensional springs characterized by an elastic stiffness $k_{\mathrm{e}}$. These components are grouped according to their type of loading (tension, compression or shear) and are 
then assembled into a mechanical model in order to evaluate the $M-\phi$ response of the whole joint. Mechanical (component) models use a set of rigid and flexible parts (springs) to simulate the interaction between the various sources of joint deformation. The springs are combined in series or in parallel depending on the way they interplay with each other. Springs in series are subjected to the same force whilst parallel springs undergo the same deformation.

The following expression can be readily derived from the code [8]:

$S_{\mathrm{j} . \mathrm{ini}}=\frac{z^{2}}{1 / k_{\mathrm{ec}}+1 / k_{\mathrm{et}}}$

whereby $z$ : lever arm; $k_{\text {ec }}$ and $k_{\text {et: }}$ stiffness of the assembly of components in the compression/shear zone and in the tension zone, respectively (Figure 8).
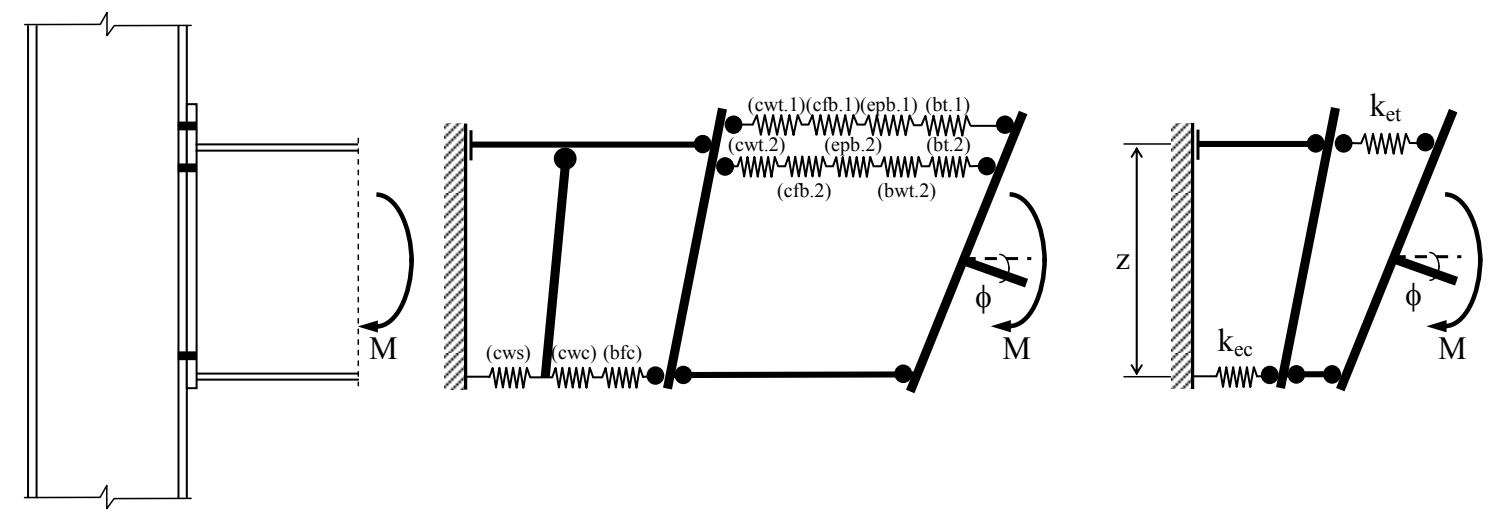

Figure 8. Component Method: Identification of Active Components and Mechanical Model Adopted in EN 1993-1-8

End plate moment connections transmit moment by coupling tension force(s) in the bolts with compression at the opposite flange. The joint design flexural resistance, $M_{\mathrm{j} . \mathrm{R}}$, in the absence of an axial force, is then calculated from simple equilibrium considerations:

$M_{\mathrm{j} . \mathrm{Rd}}=\sum_{i=1}^{n} F_{\mathrm{ti} . \mathrm{Rd}} h_{i}$

where $F_{\text {ti.R }}$ : resistance of bolt row $i$ in the tension zone [8] and $h_{i}$ : distance of the $i$-th bolt row from the centre of compression (subscript "d" indicates "design value").

Table 3 compares the code predictions with the experiments (subscripts "EC3" and "exp", respectively). The code overestimates structural stiffness properties. This is in line with experimental evidence from connections made up of mild steels [12]. The predictions for resistance compare well with test results.

The code recommendations on rotation capacity are also verified (Table 3). EN 1993-1-8 simply gives some guidelines on the subject: a bolted end plate joint may be assumed to have sufficient rotation capacity for global plastic analysis, provided that both of the following criteria are satisfied: (i) the moment resistance of the joint is governed by the resistance of either the column flange or the end plate in bending and (ii) the maximum (subscript "max") thickness $t$ of either the column flange or end plate - not necessarily the same component as (i) - fulfils:

$t_{\max }=0.36 \phi_{\mathrm{b}} \sqrt{f_{\mathrm{u} . \mathrm{b}} / f_{\mathrm{y}}}$ 
where $\phi_{\mathrm{b}}$ : bolt diameter; $f_{\mathrm{u} . \mathrm{b}}$ : tensile strength of the bolt and $f_{\mathrm{y}}$ : yield stress of the relevant basic component. These guidelines are yet insufficient to ensure adequate ductility in partial-strength joints.

Table 3. EN 1993-1-8 Predictions of the Structural Properties of the Joints Tested and Ratio to the Experiments

\begin{tabular}{|c|c|c|c|c|c|c|c|c|}
\hline \multirow[t]{2}{*}{ Test ID } & \multicolumn{3}{|c|}{ Stiffness (kNm/mrad) } & \multicolumn{3}{|c|}{ Resistance $(\mathrm{kNm})$} & \multicolumn{2}{|r|}{ Rotation capacity } \\
\hline & $S_{\text {j.ini.EC3 }}$ & $S_{\mathrm{j} . \text { ini.exp }}$ & Ratio & $M_{\mathrm{j} . \text { R.EC3 }}$ & $M_{\mathrm{j} . R . \exp }$ & Ratio & $\begin{array}{l}t_{\text {ep.max }} \\
(\mathrm{mm}) \\
\end{array}$ & Eq. (3) verifies? \\
\hline F1EP_15_1 & 23.3 & 18.4 & 1.27 & 149 & 192 & 0.78 & 14.78 & No. $\left(t_{\mathrm{ep}}=15.30 \mathrm{~mm}\right)$ \\
\hline F2EP_15_1 & 23.9 & 12.7 & 1.88 & 152 & 128 & 1.19 & 14.78 & No. $\left(t_{\mathrm{ep}}=15.30 \mathrm{~mm}\right)$ \\
\hline EEP $15 \overline{1}$ & 58.7 & 30.0 & 1.96 & 244 & 270 & 0.90 & 12.05 & No. $\left(t_{\mathrm{ep}}=15.25 \mathrm{~mm}\right)$ \\
\hline F1EP_15_2 & 22.6 & 14.1 & 1.60 & 167 & 175 & 0.95 & 11.67 & No. $\left(t_{\mathrm{ep}}=14.75 \mathrm{~mm}\right)$ \\
\hline F2EP_-15_2 & 21.5 & 12.3 & 1.75 & 164 & 160 & 1.03 & 11.67 & No. $\left(t_{\mathrm{ep}}=14.64 \mathrm{~mm}\right)$ \\
\hline EEP $15 \_2$ & 58.0 & 35.3 & 1.64 & 369 & 245 & 1.51 & 11.67 & No. $\left(t_{\mathrm{ep}}=14.62 \mathrm{~mm}\right)$ \\
\hline F1EP_10_2 & 12.4 & 7.8 & 1.59 & 104 & 95 & 1.09 & 12.29 & Yes. $\left(t_{\mathrm{ep}}=10.15 \mathrm{~mm}\right)$ \\
\hline F2EP_10_2 & 12.4 & 7.2 & 1.72 & 104 & 89 & 117 & 12.29 & Yes. $\left(t_{\mathrm{ep}}=10.25 \mathrm{~mm}\right)$ \\
\hline EEP_10_- $2 \mathrm{a}$ & 31.9 & 17.2 & 1.85 & 184 & 173 & 1.06 & 12.29 & Yes. $\left(t_{\mathrm{ep}}=10.10 \mathrm{~mm}\right)$ \\
\hline $\mathrm{EEP}_{-}^{-} 10 \_2 \mathrm{~b}$ & 34.3 & 19.9 & 1.72 & 184 & 188 & 0.98 & 10.03 & No. $\left(t_{\mathrm{ep}}=10.10 \mathrm{~mm}\right)$ \\
\hline F1EP_10_3 & 11.8 & 9.3 & 1.27 & 138 & 171 & 0.81 & 10.53 & Yes. $\left(t_{\mathrm{ep}}=10.00 \mathrm{~mm}\right)$ \\
\hline F2EP_10_3 & 12.3 & 8.0 & 1.54 & 140 & 155 & 0.90 & 10.53 & Yes. $\left(t_{\mathrm{ep}}=10.00 \mathrm{~mm}\right)$ \\
\hline EEP $\_\overline{1} 0 \_\overline{3}$ & 31.9 & 20.7 & 1.54 & 247 & 235 & 1.05 & 10.53 & Yes. $\left(t_{\mathrm{ep}}=10.00 \mathrm{~mm}\right)$ \\
\hline F2EP 10 2(M27) & 12.1 & 7.2 & 1.68 & 101 & 98 & 1.03 & 11.71 & $\mathrm{p}=10.05 \mathrm{~mm})$ \\
\hline EEP $10 \overline{2}$ (M27) & 32.8 & 23.2 & 1.41 & 184 & 195 & 0.94 & 11.71 & Yes. $\left(t_{\mathrm{ep}}=10.10 \mathrm{~mm}\right)$ \\
\hline F2EP_10_3(M27) & 12.1 & 10.9 & 1.11 & 137 & 123 & 1.11 & 10.03 & Yes. $\left(t_{\mathrm{ep}}=10.00 \mathrm{~mm}\right)$ \\
\hline EEP $\overline{10} \overline{3}$ (M27) & 32.8 & 23.0 & 1.43 & 247 & 253 & 0.98 & 10.03 & Yes. $\left(t_{\mathrm{ep}}=10.03 \mathrm{~mm}\right)$ \\
\hline
\end{tabular}

\section{CONSIDERATIONS ON THE JOINT DUCTILITY}

Analysis and design of steel frameworks are usually carried out under the semi-continuous/partially-restrained philosophy. The consistency of this type of structural modelling requires the establishment of accurate criteria regarding (i) the rotation capacity and (ii) the ductility of the joints. The rotation capacity is the angle through which the joint can rotate for a given resistance level without failing [8]. The ductility properties of a joint reflect the length of the yield plateau of the moment-rotation response. Both criteria should be based on the mechanical and geometrical characteristics of the joint components.

To meet the criterion for rotation capacity, the available joint rotation must be higher than the required joint rotation. For mild steel grades, it is generally accepted that a minimum of 35-40 mrad ensures "sufficient rotation capacity" of a bolted joint in a partial-strength scenario. Wilkinson et al. suggest that a moment connection in steel moment resisting frames in a seismic area must develop a minimum plastic rotation, $\phi_{\mathrm{p}}$, of $30 \mathrm{mrad}$ [24]. The validation of this criterion for HPS however requires further investigation. Table 4 computes the experimental values of joint plastic rotation, which corresponds to the difference between the ultimate joint rotation, $\phi_{C}$, and the first yielding rotation, $\phi_{\mathrm{y}}[7]$ :

$\phi_{\mathrm{y}}=\frac{2 / 3 M_{\mathrm{j} . \mathrm{R}}}{S_{\mathrm{j} . \mathrm{nin}}}$

Previous experimental results from tests carried out by the authors [12,26,27] are also included in this table. Tests FS1 and FS4 correspond to a bolted end plate connection between a beam IPE300, 
steel grade S355, and a rigid column. The test configuration is similar to the extended end plate specimens reported herein. The end plates had a $10 \mathrm{~mm}$ thickness and employed steel S355 in test FS1 and S690 in test FS4.

In general, thinner end plates meet the above criterion.

The requirements for ductility ensure that brittle failures are avoided, i.e. the inelastic deformations are sufficiently large. The joint ductility strongly depends on the material performance (for plates and bolts). Nowadays, the quality of HPS meets similar standards to mild steel grades. Uniaxial tension tests on HPS coupons have shown that these steels can achieve elongations at fracture up to $20 \%$, which is considered excellent $[18,25]$. However, the assurance of a good material ductility does not necessarily imply that the whole structure will behave ductile. The behaviour of steel is strongly dependent on the load history and the presence of residual strains due to prior occurrence of large deformations.

The ductility can be quantified by means of the joint ductility index $\vartheta_{\mathrm{j}}$ that relates the rotation capacity of the joint, $\phi_{\mathrm{C}}$ to the rotation value corresponding to the joint plastic resistance, $\phi_{M \mathrm{j} . \mathrm{R}}$ $[12,26]$ :

$\vartheta_{\mathrm{j}}=\frac{\phi_{\mathrm{C}}}{\phi_{M_{\mathrm{j} . \mathrm{R}}}}$

Table 4 evaluates the joint ductility index $\vartheta_{\mathrm{j}}$ for the several specimens. Experimentally, the rotation capacity was defined at the rotation level for which failure of one or more components occurred.

Table 4 also includes the rotation values at maximum load and the corresponding ductility levels, $\vartheta_{\text {j.max load: }}$

$\vartheta_{\mathrm{j} . \text { max load }}=\frac{\phi_{M_{\mathrm{j} \text { max }}}}{\phi_{M_{\mathrm{j}, \mathrm{R}}}}$

Some conclusions can be drawn from the analysis of the values in Table 4:

1. Within the same test series, the ductility indexes are similar for both flush end plate configurations; this means that the welding detail did not play an important role in the joint behaviour.

2. The extended end plate configuration yields higher ductility indexes but lower rotation capacity, except for specimens with $15 \mathrm{~mm}$ end plates.

3. Bolts 8.8 ensure a more ductile behaviour when compared to bolts 12.9 (see results for specimens EEP_10_2a and EEP_10_2b.

In order to investigate the influence of HPS grades in the deformation demand of a joint when inserted into a braced frame, a simple beam model is analysed (Figure 9a). Beam length, $L_{\mathrm{b}}$, is taken as $20 h_{\mathrm{b}}$ and $50 h_{\mathrm{b}}\left(h_{\mathrm{b}}\right.$ : beam section height). Rotational springs at the beam ends simulate the connection to the column. The beam is subjected to a uniformly distributed load, $q$. With partial-strength joints, the beam flange remains elastic and the first plastic hinges are formed in the joints. The third plastic hinge is formed in the mid-span, provided that the joint delivers enough rotation. 
Table 4. Experimental Evaluation of the Joint Ductility Indices $\vartheta_{\mathrm{j} \text {.max load }}$ and $\vartheta_{\mathrm{j}}$ and the Plastic Rotation Supply $\phi_{\text {p.u }}$

\begin{tabular}{|c|c|c|c|c|c|c|c|}
\hline Test ID & $\begin{array}{c}\phi_{y \cdot \exp } \\
(\mathrm{mrad})\end{array}$ & $\begin{array}{l}\phi_{M j . R . e x p} \\
(\mathrm{mrad})\end{array}$ & $\begin{array}{l}\phi_{\mathrm{Mj} . \max } \\
(\mathrm{mrad})\end{array}$ & $\begin{array}{c}\phi_{\text {C.exp }} \\
(\mathrm{mrad})\end{array}$ & $\begin{array}{c}\phi_{\text {p.u.exp }} \\
(\mathrm{mrad})\end{array}$ & $\vartheta_{j . \max \text { load }}$ & $\vartheta_{j}$ \\
\hline F1EP_15_1 & 7 & 12 & 33 & 33 & 26 & 2.75 & 2.75 \\
\hline F2EP 15 & 7 & 10 & 32 & 40 & 33 & 3.20 & 4.00 \\
\hline EEP $15 \overline{1}$ & 6 & 9 & 28 & 28 & 22 & 3.11 & 3.11 \\
\hline F1EP_15_2 & 8 & 12 & 34 & 37 & 29 & 2.83 & 3.08 \\
\hline F2EP 152 & 9 & 13 & 33 & 39 & 30 & 2.54 & 3.00 \\
\hline EEP_15_2 & 5 & 7 & 20 & 20 & 15 & 2.86 & 2.86 \\
\hline F1EP_10_2 & 8 & 12 & 39 & 46 & 38 & 3.25 & 3.83 \\
\hline F2EP 102 & 8 & 12 & 35 & 41 & 33 & 2.92 & 3.42 \\
\hline EEP $10 \_\overline{2} \mathrm{a}$ & 7 & 10 & 36 & 45 & 38 & 3.60 & 4.50 \\
\hline $\mathrm{EEP} 10 \_2 \mathrm{~b}$ & 6 & 9 & 37 & 46 & 40 & 4.11 & 5.11 \\
\hline F1EP_10_3 & 12 & * & 46 & 46 & 34 & - & 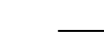 \\
\hline F2EP_10_3 & 13 & * & 52 & - & - & - & - \\
\hline EEP_10_3 & 8 & 11 & 38 & 38 & 30 & 3.45 & 3.45 \\
\hline F2EP_10_2(M27) & 9 & 14 & 38 & 38 & 29 & 2.71 & 2.71 \\
\hline $\mathrm{EEP} 10 \_2(\mathrm{M} 27)$ & 6 & 9 & 30 & 52 & 46 & 3.33 & 5.78 \\
\hline F2EP $10 \quad 3(\mathrm{M} 27)$ & 8 & 14 & 42 & 67 & 59 & 3.00 & 4.79 \\
\hline $\mathrm{EEP} \_10 \_3(\mathrm{M} 27)$ & 7 & 12 & 31 & 44 & 37 & 2.58 & 3.67 \\
\hline FS1 & 5 & 7 & 77 & 111 & 106 & 11.9 & 17.1 \\
\hline FS4 & 7 & 10 & 44 & 64 & 57 & 4.6 & 6.8 \\
\hline
\end{tabular}

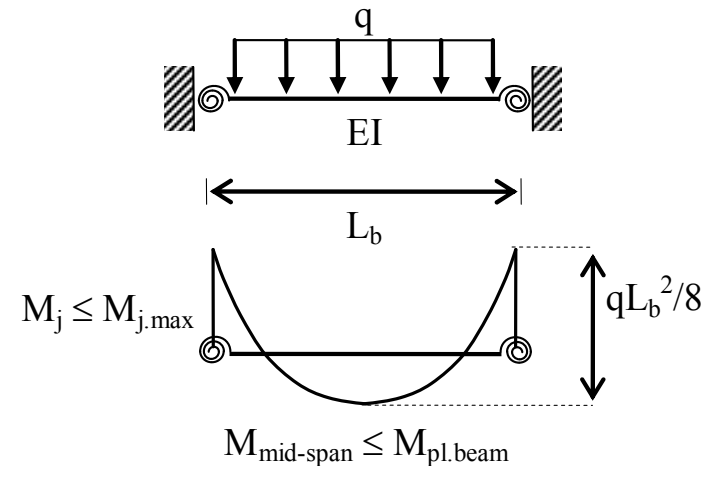

(a) Beam: Parameters

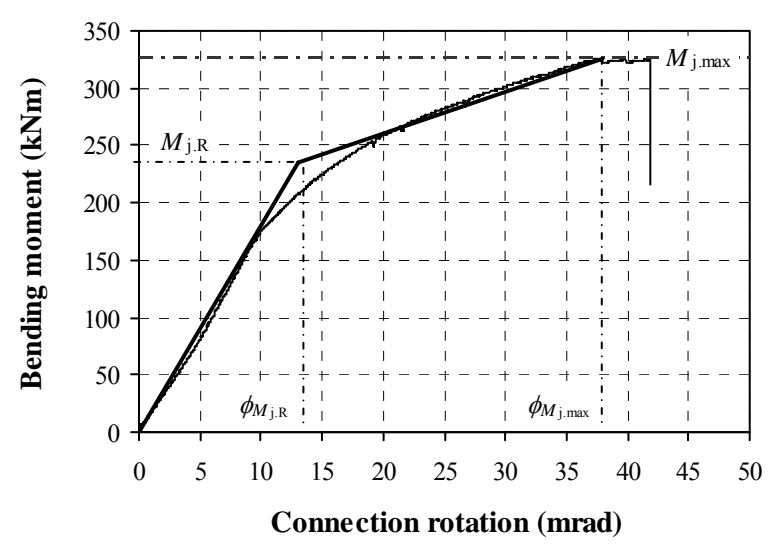

(i) e.g. EEP_10_3

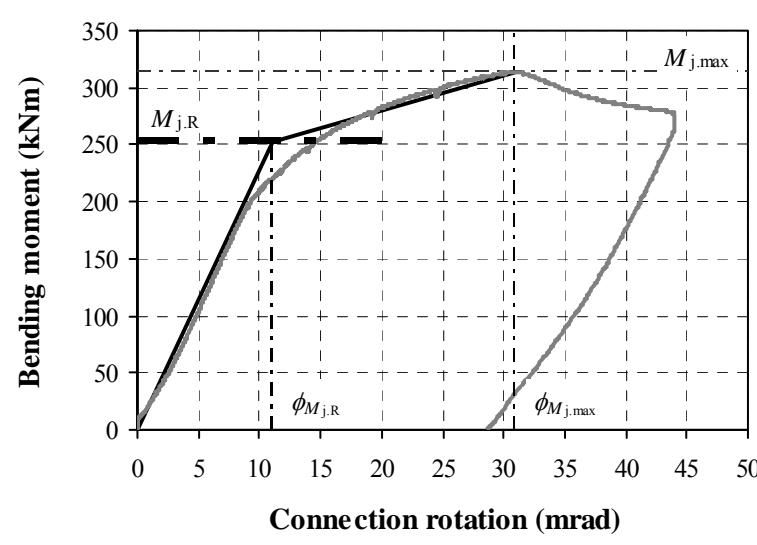

(ii) e.g. EEP_10_3(M27)

(b) Moment-rotation Characteristics of the Joints: Actual Behaviour and Bilinear Approximation Figure 9. Beam Model 
The actual profiles from the tested specimens are adopted in the analysis. For good comparison of results, a modification to the actual beam mechanical behaviour is introduced. All the above connections use a beam of grade S355. An actual frame however would employ beams and end plates of similar steel grade, i.e. end plates S690 and beams S690, for instance. In this analysis, the steel grade of the beam and the end plate is identical. This solution was not adopted in the tests because rolled profiles of steel grades S690 and S960 are hardly economically available for research purposes. For this beam-end plate steel grades combination, the degree of partial-strength reduces considerably.

The actual behaviour of the various joints is approximated by a simplified bilinear relationship (Figures 5 and 9b). Joints F2EP_15_1, F2EP_15_2, EEP_10_2a, EEP_10_3, EEP_10_2(M27), EEP_10_3(M27), FS1 and FS4 are used for further comparisons.

The results of this analysis are set out in Tables 5-6 and plotted in the graphs from Figures $10\left(L_{\mathrm{b}}=\right.$ $50 h_{\mathrm{b}}$ in all graphs) and 11 , in terms of connection rotation vs. ratio $\varsigma=q L_{\mathrm{b}}{ }^{2} / M_{\text {pl.beam. }}$. Figure 11 , in particular, shows that the beam span length mainly influences the results in the post-yield behaviour domain of the joints. Load $q$ is incremented from zero until (i) a plastic hinge is formed in the mid-span $\left(M_{\text {mid-sp }}=M_{\text {pl.beam }}\right)$ or (ii) the maximum rotation of the joints is reached. In all cases, the second condition governs (Tables 5 and 6, sixth column). For each test, the plastic moment of the beam section is computed as follows:

$M_{\text {pl.beam }}=W_{\text {pl.b }} f_{\text {y.ep.nom }}$

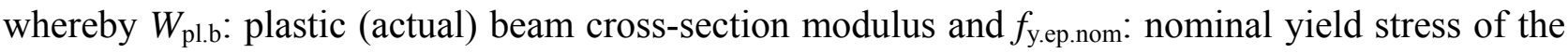
corresponding end plate (Table 7, second and third columns).

Table 5: Results from the Beam Analysis for $L_{\mathrm{b}}=20 h_{\mathrm{b}}$

\begin{tabular}{|c|c|c|c|c|c|}
\hline \multirow[t]{2}{*}{ Test ID } & \multirow{2}{*}{$\begin{array}{l}\phi(\mathrm{mrad}) \\
(\varsigma=2.5)\end{array}$} & \multirow{2}{*}{$\begin{array}{c}\varsigma \\
(\phi=30 \mathrm{mrad})\end{array}$} & \multicolumn{3}{|c|}{ Failure conditions $\left(\phi=\phi_{M_{\mathrm{j} \text { max }}}\right)$} \\
\hline & & & $q_{\mathrm{u}}(\mathrm{kN} / \mathrm{m})$ & $M_{\mathrm{j}} / M_{\text {pl.beam }}$ & $M_{\text {mid-sp }} / M_{\text {pl.beam }}$ \\
\hline F2EP_15_1 & 8.9 & 4.9 & 98.0 & 0.23 & 0.41 \\
\hline F2EP 152 & 14.7 & 3.7 & 113.0 & 0.19 & 0.30 \\
\hline EEP_10_2a & 11.9 & 3.9 & 126.0 & 0.22 & 0.33 \\
\hline EEP_10_3 & 15.9 & 3.4 & 154.0 & 0.21 & 0.28 \\
\hline EEP_10_2(M27) & 8.8 & 4.3 & 124.0 & 0.24 & 0.31 \\
\hline EEP $10 \_3(\mathrm{M} 27)$ & 14.1 & 3.5 & 140.0 & 0.20 & 0.24 \\
\hline FS1 & 2.9 & 7.5 & 65.0 & 0.72 & 0.59 \\
\hline FS4 & 5.4 & 5.3 & 69.0 & 0.44 & 0.28 \\
\hline
\end{tabular}

Table 6: Results from the Beam Analysis for $L_{\mathrm{b}}=50 h_{\mathrm{b}}$

\begin{tabular}{lrrrrr}
\hline \multicolumn{1}{c}{ Test ID } & $\phi(\mathrm{mrad})$ & \multicolumn{5}{c}{$\varsigma$} & \multicolumn{3}{c}{ Failure conditions $\left(\phi=\phi_{M_{\mathrm{j} \text { max }}}\right)$} \\
& $(\varsigma=2.5)$ & $(\phi=30 \mathrm{mrad})$ & $q_{\mathrm{u}}(\mathrm{kN} / \mathrm{m})$ & $M_{\mathrm{j}} / M_{\text {pl.beam }}$ & $M_{\text {mid-sp }} / M_{\text {pl.beam }}$ \\
\hline F2EP_15_1 & 12.3 & 3.6 & 11.3 & 0.23 & 0.23 \\
F2EP_15_2 & 23.7 & 2.8 & 13.5 & 0.19 & 0.18 \\
\hline EEP_10_2a & 19.6 & 3.1 & 15.3 & 0.22 & 0.20 \\
EEP_10_3 & 24.3 & 2.7 & 19.5 & 0.21 & 0.17 \\
EEP_10_2(M27) & 13.2 & 3.4 & 15.8 & 0.24 & 0.19 \\
EEP_10_3(M27) & 21.9 & 2.8 & 18.1 & 0.20 & 0.15 \\
\hline FS1 & 2.9 & 7.1 & 9.2 & 0.72 & 0.45 \\
FS4 & 5.4 & 5.1 & 10.5 & 0.44 & 0.25 \\
\hline
\end{tabular}




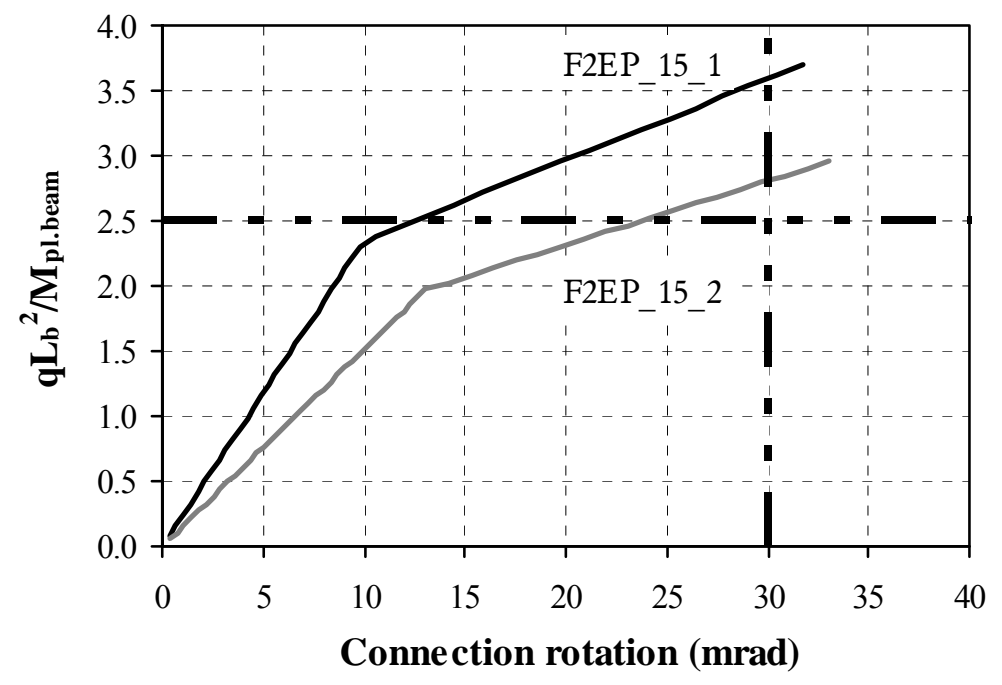

(a) Specimens F2EP

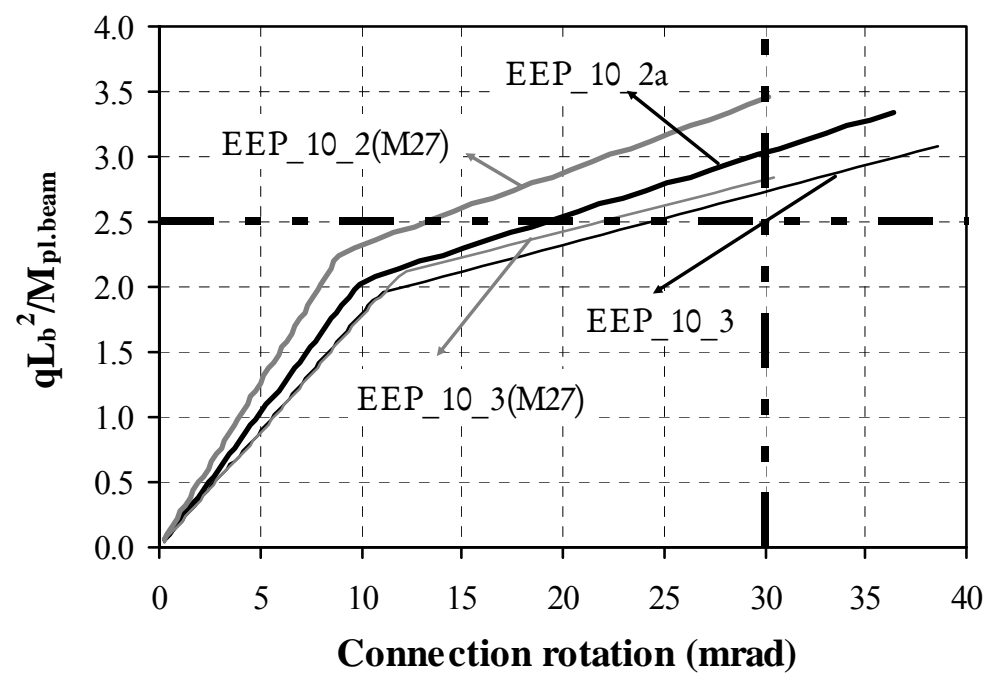

(b) Specimens EEP

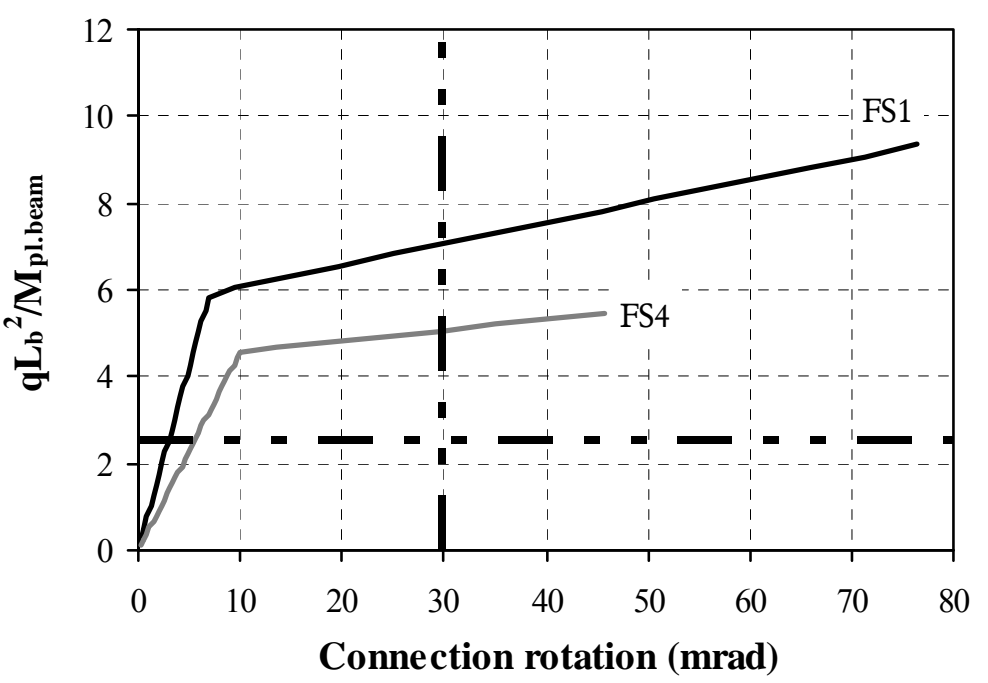

(c) Specimens FS1 and FS4

Figure 10. Behaviour "Available Rotation Capacity" vs. "Ratio $q L_{\mathrm{b}}{ }^{2} / M_{\text {pl.beam }}$ " $\left(L_{\mathrm{b}}=50 h_{\mathrm{b}}\right)$ 
The ratio $\varsigma=q L_{\mathrm{b}}{ }^{2} / M_{\text {pl.beam }}$ gives an idea of the degree of utilization of the beam. The graphs in Figure 10 highlight the demand for higher rotations in higher steel grades for the same value of $\varsigma$. Tables 5 and 6 that compare the joint rotation for such a ratio of 2.5 (second column) clearly show this tendency. If now the results are compared for a specific rotation of $30 \mathrm{mrad}$, for example (third column on Tables 5 and 6) the values of the above ratio decrease with the end plate yield stress. The failure conditions, for $\phi=\phi_{\mathrm{Mj} \text {.max }}$, are also characterized, in terms of maximum load, $q_{\mathrm{u}}$, the bending moment acting (i) at the joints $M_{\mathrm{j}}$ and (ii) at mid-span $M_{\text {mid-sp }}$, computed with reference to the plastic moment of the beam section. The ratio $M_{\mathrm{j}} / M_{\text {pl.beam }}$ corresponds to the degree of joint partial-strength. As expected, the maximum load increases when higher stress steel grades are employed. But, the degree of joint partial-strength decreases and the beam efficiency reduces. Finally, Table 7 compares the increase in steel grade for the various specimens and the corresponding increase in load capacity. This correspondence is not comparable. Taking specimen EEP_10_2(M27) (S690) and EEP_10_3(M27) (S960) as example, the improvement in steel grade is $40 \%$ whilst the maximum load only increases $10 \%$.

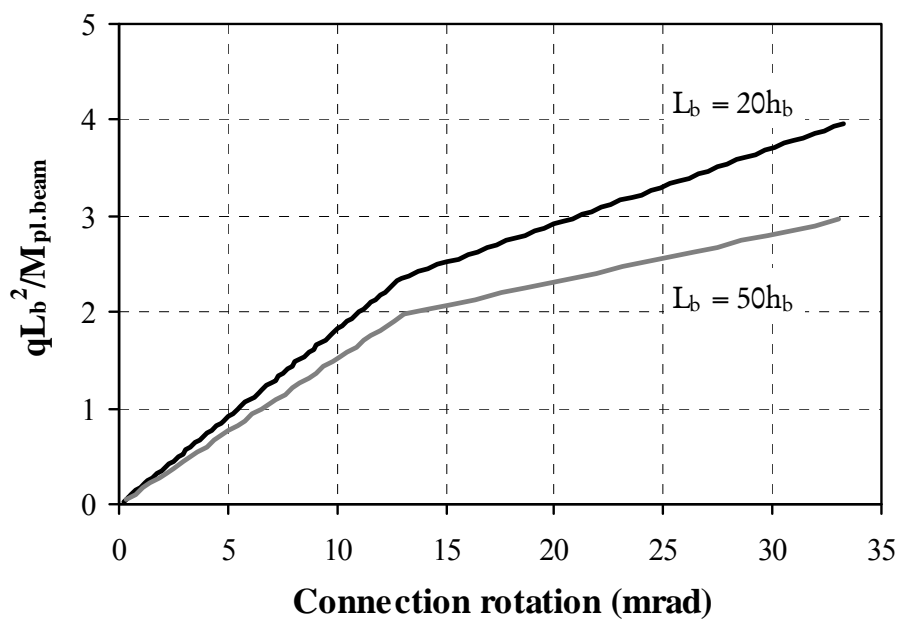

Figure 11. F2EP_15_2: "Behaviour Available Rotation Capacity" vs. "Ratio $q L_{\mathrm{b}}{ }^{2} / M_{\text {pl.beam }}$ " for Different Beam Spans

Table 7. Computation of the Increase in Stele Grade and Corresponding Increase in Maximum Load

\begin{tabular}{|c|c|c|c|c|c|}
\hline Test ID & $f_{\text {y.ep.nom }}(\mathrm{MPa})$ & $M_{\text {pl.beam }}(\mathrm{kNm})$ & $\begin{array}{c}\text { Increase } \\
\text { in steel grade }\end{array}$ & $q_{\mathrm{u}}(\mathrm{kN} / \mathrm{m})$ & $\begin{array}{c}\text { Increase } \\
\text { in max. load }\end{array}$ \\
\hline F2EP_15_1 & 460 & 749 & \multirow{2}{*}{1.5} & 11.3 & \multirow{2}{*}{1.2} \\
\hline F2EP $15-2$ & 690 & 1123 & & 13.5 & \\
\hline EEP_10_2a & 690 & 1123 & \multirow{2}{*}{1.4} & 15.3 & \multirow{2}{*}{1.3} \\
\hline EEP 103 & 960 & 1563 & & 19.5 & \\
\hline EEP_10_2(M27) & 690 & 1123 & \multirow{2}{*}{1.4} & 15.8 & \multirow{2}{*}{1.1} \\
\hline EEP_10_3(M27) & 960 & 1563 & & 18.1 & \\
\hline FS1 & 355 & 223 & \multirow{2}{*}{1.9} & 9.2 & \multirow{2}{*}{1.1} \\
\hline FS4 & 690 & 433 & & 10.5 & \\
\hline
\end{tabular}




\section{CONCLUSIONS}

The primary goals of this research work were (i) the experimental characterization, (ii) the validation of current Eurocode 3 specifications for mild steels and (iii) the deformation analysis of HPS moment connections.

Comparison of test results with EN 1993-1-8 procedures for the design of joints within the semi-continuous/partially-restrained concept shows that (i) the T-stub idealization of the tension zone of moment connections adopted in EN 1993-1-8 gives accurate results in terms of prediction of the design resistance even when HPS grades are employed, (ii) the stiffness properties are overestimated and (iii) the guidelines for verification of sufficient rotation capacity can be quite conservative in some cases (Tables 3 and 4).

It was found out that the rotation capacity of the connection specimens using HPS satisfy high deformation demands. Plastic rotation capacities of $30 \mathrm{mrad}$ (and above) were achieved with thinner end plates and $15 \mathrm{~mm}$ flush end plates. However, a simple beam analysis with actual joint behaviour has shown that (i) the efficiency of HPS moment connections has no correspondence to the improvement in steel quality and (ii) the deformation demands of these connections are higher than for mild steel grades. Both aspects must further be looked into in order to establish accurate ductility and deformation requirements that allow the designer to take full advantage in the use of this new family of constructional steels. The next logical step forward to this investigation is the numerical implementation of these joint configurations to propose simple expressions for evaluation of the rotation capacity based on geometrical and mechanical parameters.

\section{ACKNOWLEDGMENTS}

Financial support from Delft University of Technology is gratefully acknowledged. The assistance provided by the staff of the Stevin Laboratory, particularly Mr. Edwin Scharp, in preparing the test specimens and their support in conducting the tests, is most appreciated.

\section{REFERENCES}

[1] Douty, R.T. and McGuire, W., "High Strength Moment Connections", Journal of Structural Division, ASCE, 1965, Vol. 91, ST2, pp. 101-128.

[2] Zoetemeijer, P., "A Design Method for the Tension Zone of Statically Loaded Bolted Beam-to-Column Connections”, Heron, 1974, Vol. 20, No. 1, pp. 1-59.

[3] Mann, A.P. and Morris, L.J., "Limit Design of Extended End Plate Connections", Journal of the Structural Division, ASCE, 1979, Vol. 105, ST3, pp. 511-526.

[4] Yee, Y.L. and Melchers, R.E., "Moment-rotation Curves for Bolted Connections", Journal of Structural Engineering, ASCE, 1985, Vol. 112, No. 3, pp. 615-635.

[5] Davison, J.B., Kirby, P.A. and Nethercot, D.A., "Rotational Stiffness Characteristics of Steel Beam-to-Column Connections", Journal of Constructional Steel Research, 1987, Vol. 8, pp. 17-54.

[6] Jaspart, J.P. and Maquoi, R., "Prediction of the Semi-rigid and Partial Strength Properties of Structural Joints", Proceedings of the Annual Technical Meeting on Structural Stability Research, Lehigh, 1994, pp. 177-191.

[7] Faella, C., Piluso, V. and Rizzano, G., "Structural Semi-rigid Connections - Theory, Design and Software", CRC Press, 2000. 
[8] European Committee for Standardization (CEN), EN 1993-1-8 - Eurocode 3: Design of Steel Structures - Part 1-8: Design of Joints, 2005.

[9] American Institute of Steel Construction (AISC), ANSI/AISC 360-05 - Specification for Structural Steel Buildings, 2005.

[10] Gioncu, V., Mateescu, G., Petcu, D. and Anastasiadis, A., "Prediction of Available Ductility by Means of Local Plastic Mechanism Method: DUCTROT Computer Program”, Chapter 2.1 in Moment Resistant Connections of Steel Frames in Seismic Areas (Ed.: F. Mazzolani), E\&FN Spon, pp. 95-146.

[11] Beg, D., Zupančič, E. and Vayas, I., "On the Rotation Capacity of Moment Connections”, Journal of Constructional Steel Research, 2004, Vol. 60, pp. 601-620.

[12] Girão Coelho, A.M., "Characterization of the Ductility of Bolted End Plate Beam-to-Column Steel Connections", PhD Thesis, University of Coimbra, 2004. Free download at: $\mathrm{http}: / / \mathrm{www} . \mathrm{cmm} . \mathrm{pt} / \mathrm{gcom} / \mathrm{publicacoes} / \mathrm{teses} / \mathrm{phd}$ thesis_ana_girao.pdf

[13] Bjorhovde, R., "Deformation Considerations for Connection Performance and Design", Proceedings of the Fifth International ECCS/AISC Workshop on Connections in Steel Structures: Innovative Steel Connections, Amsterdam, 2004, pp. 11-20.

[14] Zoetemeijer, P., "Summary of the Research on Bolted Beam-to-Column Connections", Report 25-6-90-2, Faculty of Civil Engineering, Stevin Laboratory - Steel Structures, Delft University of Technology, 1990.

[15] Jaspart, J.P., "Contributions to Recent Advances in the Field of Steel Joints - Column Bases and Further Configurations for Beam-to-Column Joints and Beam Splices", Aggregation Thesis, University of Liège, 1997.

[16] Swanson, J.A., "Characterization of the Strength, Stiffness and Ductility Behaviour of T-stub Connections", PhD Thesis, Georgia Institute of Technology, 1999.

[17] Kuhlmann, U. and Kühnemund, F., "Ductility of Semi-rigid Steel Joints", Proceedings of the International Colloquium on Stability and Ductility of Steel Structures (SDSS 2002), Budapest, 2002, pp. 363-370.

[18] Günther, H-P. (Ed.), "Use and Application of High-performance Steels for Steel Structures", International Association for Bridge and Structural Engineering (IABSE), Structural Engineering Documents, 2005, Vol. 8.

[19] European Committee for Standardization (CEN), prEN 1993-1-12 - Eurocode 3: Design of Steel Structures - Part 1-12: Additional Rules for the Extension of EN 1993 up to Steel Grades S700; 2005.

[20] European Committee for Standardization (CEN), EN 1993-1-1 - Eurocode 1: Design of Steel Structures - Part 1-1: General Rules and Rules for Buildings, 2005.

[21] Girão Coelho, A.M. and Bijlaard, F.S.K., "Experimental Behaviour of High Performance Steel Moment Connections", Report 6-06-5, Faculty of Civil Engineering, Stevin Laboratory - Steel Structures, Delft University of Technology, 2006.

[22] Girão Coelho, A.M. and Bijlaard, F.S.K., "Experimental Behaviour of High Strength Steel end Plate Connections", Journal of Constructional Steel Research, 2007, Vol. 63, pp. 1228-1240.

[23] Zandonini, R. and Zanon, P., "Experimental Analysis of End Plate Connections", Proceedings of the First International ECCS/AISC Workshop on Connections in Steel Structures: Behaviour, Strength and Design, Cachan, 1988, pp. 40-51.

[24] Wilkinson, S., Hurdman, G. and Crowther, A., "A Moment Resisting Connection for Earthquake Resistant Structures", Journal of Constructional Steel Research, 2006, Vol. 62, pp. 295-302.

[25] Bjorhovde, R., "Development and Use of High Performance Steel”, Journal of Constructional Steel Research, Vol. 60, 2004, pp. 393-400. 
[26] Girão Coelho, A.M., Simões da Silva, L. and Bijlaard, F.S.K., "Ductility Analysis of Bolted Extended End Plate Beam-to-Column Connections in the Framework of the Component Method", Steel and Composite Structures, 2006, Vol. 6, No. 1, pp. 33-53.

[27] Girão Coelho, A.M., Bijlaard, F.S.K. and Simões da Silva, L., "Experimental Assessment of the Ductility of Extended End Plate Connections", Engineering Structures, 2004, Vol. 26, pp. 1185-1206.

\section{NOMENCLATURE}

\section{Lower cases}

$a_{\mathrm{w}}$

$f_{\mathrm{u}}$

$f_{\mathrm{y}}$

$h$

$h_{i}$

$k_{\mathrm{e}}$

$k_{\text {ec }}$

$k_{\text {et }}$

$n$

$q$

$t$

Z

\section{Upper cases}

\section{E}

$F_{\text {ti.R }}$

$L$

M

$M_{\mathrm{j} . \mathrm{R}}$

$M_{\text {j.max }}$

$M_{\not C}$

$S_{\text {j.ini }}$

$S_{\text {j.p-1 }}$

$W_{\mathrm{pl}}$

\section{$\underline{\text { Greek letters }}$}

$\varepsilon_{\mathrm{f}}$

$\phi$

$\phi_{\mathrm{b}}$

$\phi_{\mathrm{C}}$

$\phi_{\text {Mj.max }}$

$\phi_{\mathrm{Mj} . \mathrm{R}}$

$\phi_{\mathrm{p}}$

$\phi_{\mathrm{y}}$

$\vartheta_{j}$

$\vartheta_{j . \max \text { load }}$

$\rho_{\mathrm{y}}$

$\varsigma$
Throat thickness of a fillet weld

Ultimate or tensile stress

Yield stress

Depth

Distance of bolt row $i$ to the centre of compression

Stiffness of an active joint component

Stiffness of the assembly of components in the compression/shear zone

Equivalent stiffness of the assembly of components in the tension zone

Number of bolt rows

Load

Thickness

Lever arm

Young modulus

Potential resistance of bolt row $i$ in the tension zone at plastic conditions

Length

Bending moment

Joint flexural plastic resistance

Maximum bending moment

Bending moment at fracture of the joint

Initial rotational stiffness of a joint

Post-yield rotational stiffness of a joint

Plastic cross-section modulus
Strain at rupture load

Connection rotational deformation

Bolt diameter

Rotation capacity of a connection

Rotation of the connection at maximum load

Connection rotation "analytical" value at which the moment resistance first reaches $M_{\mathrm{j} . \mathrm{R}}$

Plastic rotation of a connection

First yielding connection rotation

Joint ductility index

Joint ductility index evaluated for the rotation at maximum load

Yield ratio

Ratio $q L_{\mathrm{b}}{ }^{2} / M_{\text {pl.beam }}$ 


\section{Subscripts}

\begin{tabular}{lll}
\hline $\mathrm{b}$ & & Beam; bolt \\
$\mathrm{d}$ & & Design value \\
$\mathrm{ep}$ & & End plate \\
$\mathrm{exp}$ & & Experimental \\
$\mathrm{EC} 3$ & Eurocode 3 \\
$\mathrm{j}$ & Joint \\
$\max$ & Maximum \\
$\operatorname{mid}-\mathrm{sp}$ & Mid-span \\
nom & Nominal value \\
$\mathrm{pl}$ & Pure plastic conditions \\
$\mathrm{u}$ & Ultimate conditions \\
$\mathrm{y}$ & Yield
\end{tabular}

